The main conclusions I have come to are:

1. The assistance to children in case of disasters should be provided by pediatric experts, since this diminishes the morbidity and mortality rate twofold;

2. Many countries of the world do not have a sufficient number of experts who can provide the specialized, qualified, medical aid to children in catastrophes;

3. The standards used for treating children in disasters differ greatly from those used for treating adults, but so far, have not been worked out thoroughly;

4. Specialized medical aid to children must be rendered maximally as close to the site of the disaster as is possible;

5. The system for the provision of specialized assistance to children in case of wars and emergencies, including legal, social, psychological, and medical, currently does not exist anywhere in the world.

To my mind, the WHO must head and regulate the medical activities during catastrophes and wars, including those activities aimed at helping children. The WHO recommendations must become the law for all non-governmental organizations and foundations. All non-governmental organizations and foundations, as well as for individual experts, involved in such activities, must get the WHO certificate giving them the right to work in the areas of disasters. This is especially important since the role of the International Committee of the Red Cross recently has faded substantially as indicated by some of the events in Iraq. Keywords: certification; children; disasters; International Committee of the Red Cross (ICRC); medical care; non-governmental organizations (NGOs); pediatrics; relief; specialists; World Health Organization (WHO)

Prehosp Disast Med 2003;18(s1)24.

\section{Protecting and Empowering Children in War Situations}

\section{Dr. Anica Mikus Kos}

The Foundation TOGETHER-Regional Centre for

Psychosocial Well-being of Children

Sadly, during armed conflicts and related events, children are exposed to the whole range of adversities, frightening events, losses, wounds, as is the rest of the civilian population. So much already has been said and written about devastating traumatic experiences of children that there is no need to repeat it. Of importance is the question of how children who can not be protected from exposure to adversities and atrocities, can be psychologically protected and psychosocially empowered to overcome their experience without long-lasting psychological consequences and psychosocial dysfunctions.

Psychosocial support to children can be integrated in the general protection of children already in place in emergency situations. Measures for the mobilisation of the child's social networks for establishing as soon as possible, some structuring activities (as improvised education for instance), creating at least a small island of safe haven, etc., are of great protective value. The natural social group, volunteers, and other lay persons can provide partial counter-measures to the impact of threatening circumstances. Children and youths can be involved in various activities for the benefit of others or of the community. Mental health professionals first of all, should assume the role of promoters of efforts and activities aimed to protect children and youth. Time is very important, and there is no need to wait for assessments of the number of traumatised children for introducing general protective measures. Often, too much resources, energy, and time are spent for various assessments that do not have an important impact on the development of immediate protective activities. Some population-oriented and community-based models of psychosocial protection of children and support to children applied in the Balkans and North Caucuses will be presented.

Keywords: children; empowerment; models; protection; psychosocial; social networks; war; youths Prehosp Disast Med 2003;18(s1)s24.

\section{Delivering Bad News in Catastrophic Medicine \\ Urska Lunder, $M D$ \\ Palliative Care Development Institute, Ljubljana, Slovenia}

Nearly every healthcare professional in catastrophic medicine is challenged by communication with victims or survivors in a very specific and sensitive manner, especially while delivering bad news. The regular course of education does not provide sufficient opportunity to gain skills and knowledge about communication in critical circumstances.

A part of a research project on teaching these specific skills will be presented. Fifty general practitioners were randomly chosen from all of the applicants who replied to our invitations to participate in the study. A pre-test/posttest design was used to evaluate the efficacy of a two-day intensive training program in delivering bad news. The participants were videotaped during interviews with trained simulated patients. The videotapes were rated by two independent raters, using an established instrument for evaluation of utterance by utterance of the communication skills and behavior before and after participation in the training program.

Results suggest that communication skills can be taught, but attitudes and emotional concerns are more difficult to change.

In this paper, data about the participants' emotional concerns and barriers will be presented. These data were gathered from questionnaires, from role playing, from comments after participants viewed their own videotaped interviews, and from narrative declarations of concerns in the participants' case reports. There is an outstanding finding that, in addition to lack of knowledge and skills, the majority of the participants felt emotionally unsupported (for themselves, and for the patients and their relatives) when dealing with critical situations. The most critical emotional states to handle are anger, profound grief, and depression.

Keywords: anger; bad news; communications; depression; emotional concerns; general practitioners; knowledge; role-playing; simulations; skills

Prebosp Disast Med 2003:18:s(1)s24.

E-mail: urska.lunder@mail.judmila.org 